\title{
Spinodal decomposition related to age-hardening and cuboidal structures in a dental low-carat gold alloy with relatively high $\mathrm{Cu} / \mathrm{Ag}$ content ratio
}

\author{
Ji-In Jeong • Hyung-Il Kim • Gwang-Young Lee • \\ Yong Hoon Kwon • Hyo-Joung Seol
}

Published online: 10 November 2013

(C) The Author(s) 2013. This article is published with open access at SpringerLink.com

\begin{abstract}
A dental $\mathrm{Au}-\mathrm{Ag}-\mathrm{Cu}-\mathrm{Pd}$ alloy with a relatively low $\mathrm{Au}$ content and a high $\mathrm{Cu} / \mathrm{Ag}$ content ratio was examined to determine the correlation between the microstructural changes by the spinodal decomposition and age-hardening behaviour using a hardness test, X-ray diffraction study, field emission scanning electron microscopy and energy-dispersive X-ray spectrometry. Separation of the parent $\alpha_{0}$ phase occurred by spinodal decomposition during aging at $350{ }^{\circ} \mathrm{C}$ after the solution treatment at $750{ }^{\circ} \mathrm{C}$, and not by a nucleation and growth mechanism, resulting in the formation of the stable Ag-rich $\alpha_{1}$ and $\mathrm{AuCu}$ I phases through a metastable state. Hardening resulted from the coherency lattice strain which occurred along the $a$-axis between the metastable Ag-rich $\alpha_{1}{ }^{\prime}$ and $\mathrm{AuCu} \mathrm{I}^{\prime}$ phases. In addition, lattice distortion occurred along the $c$-axis between the stable Ag-rich $\alpha_{1}$ and $\mathrm{AuCu}$ I phases due to the tetragonality of the $\mathrm{AuCu}$ I ordered phase. The transformation of the stable Ag-rich $\alpha_{1}$ and $\mathrm{AuCu}$ I phases from the metastable state introduced the formation of the fine and uniform cuboidal structures, which compensated for the increased gap in the lattice parameters through the phase transformation. Replacement of the fine cuboidal structures with the coarser lamellar structures occurred without a phase transformation, and resulted in softening by reducing the interfaces between the stable Ag-rich $\alpha_{1}$ and $\mathrm{AuCu}$ I phases.
\end{abstract}

Keywords Spinodal decomposition · Cuboidal structures . Age-hardening $\cdot \mathrm{X}$-ray diffraction $\cdot$ Metastable AuCu I' phase

J.-I. Jeong • H.-I. Kim • G.-Y. Lee • Y. H. Kwon • H.-J. Seol ( $₫)$ Department of Dental Materials, Institute of Translational Dental Science, School of Dentistry, Pusan National University, Beomeo-Ri, Mulgeum-Eup, Yangsan-Si, Gyeongsangnam-Do 626-814,

South Korea

e-mail: seolhyojoung@daum.net

\section{Introduction}

Dental prostheses made with dental alloys must have sufficient mechanical properties to bear the stress from mastication. For that reason, dental alloys are subjected to proper heat treatment to be age-hardened. The hardening mechanism shows a range of aspects depending on the chemical composition of alloys [1]. In $\mathrm{Au}-\mathrm{Ag}-\mathrm{Cu}$ alloys, hardening occurs through the combined effects of ordering by the $\mathrm{Au}-\mathrm{Cu}$ system and phase decomposition by the $\mathrm{Ag}-\mathrm{Cu}$ system. In addition, such a hardening process can occur by spinodal decomposition in $\mathrm{Au}-\mathrm{Ag}-\mathrm{Cu}$ alloys under a specific composition and temperature range. Hamasaki et al. [2] reported that the precipitation of the metastable $\mathrm{Cu}_{3} \mathrm{Au}$ ordered phase and spinodal decomposition were represented by two types of solution treatment temperatures, which resulted in different aging behaviours in the alloy composed of $45 \mathrm{Au}-24.5$ Ag-24.5 Cu-5 Pd-1 Pt (wt.\%). Nakagawa and Yasuda [3] reported three types of age-hardening behaviours depending on aging temperatures in the alloy composed of $27.4 \mathrm{Au}-17.4$ Ag-55.2 Cu (at.\%): (1) a dual mechanism of spinodal decomposition and $\mathrm{Cu}_{3} \mathrm{Au}$ ordering, (2) a single mechanism of spinodal decomposition, and (3) a single mechanism of nucleation and growth of silver-rich precipitates.

The alloy that was age-hardened by spinodal decomposition showed finer and uniform structures than those induced by a nucleation and growth mechanism $[4,5]$. Such fine microstructures will be beneficial to the tarnish and corrosion resistance as well as the biocompatibility for the use of these alloys in dental practice. In addition, a softening mechanism, such as a grain boundary reaction, can be more delayed than that by a nucleation and growth mechanism due to the formation of the microstructures that are similar to the single-phased structures [6]. Therefore, heat treatment 
conditions for hardening are less influenced by the aging time due to a delay of the grain boundary reaction. On the other hand, the correlation between the microstructural changes by spinodal decomposition and the age-hardening behaviours of the alloys has not been elucidated completely. Therefore, it is not easy to control both the microstructures and hardness for the optimal conditions in dental practice.

This study examined the age-hardening behaviour of an $\mathrm{Au}-\mathrm{Ag}-\mathrm{Cu}-\mathrm{Pd}$ alloy with a relatively low $\mathrm{Au}$ content and a high $\mathrm{Cu} / \mathrm{Ag}$ content ratio, which has the possibility of agehardening by spinodal decomposition. The purpose of this study was to elucidate the spinodal decomposition related to age-hardening and cuboidal structures in a dental low-carat gold alloy composed of $31.88 \mathrm{Au}-39.58 \mathrm{Ag}-23.71 \mathrm{Cu}-3.54$ $\mathrm{Pd}$ (at.\%) with minor ingredients using a hardness test, X-ray diffraction study, field emission scanning electron microscopy and energy-dispersive X-ray spectrometry.

\section{Materials and methods}

Specimen alloy

The specimen used in this study was a commercial type III dental low-carat gold alloy (AURIUM 50Y, Aurium ${ }^{\circledR}$ Research U.S.A., San Diego, CA, USA) according to the ISO classification (ISO 22674: 2006 (E)). This type of alloy is based on the ternary system of $\mathrm{Au}, \mathrm{Ag}$ and $\mathrm{Cu}$ for the fabrication of single units and long bridges. The condition of the hardening heat treatment indicated by the manufacturer was $350{ }^{\circ} \mathrm{C}$ for $15 \mathrm{~min}$. Table 1 lists composition of the specimen alloy in weight percent, which was supplied by the manufacturer. The sum of the $\mathrm{Zn}$ and Ir content was $1 \mathrm{wt} . \%$. Therefore, the atomic ratio for these elements was converted from the values that were set to $0.5 \mathrm{wt} . \%$, respectively.

\section{Heat treatment}

The specimens were subjected to a solution treatment to obtain a supersaturated solid solution of a single phase at $750{ }^{\circ} \mathrm{C}$ for $15 \mathrm{~min}$ in a vertical furnace under an argon atmosphere to inhibit oxidation, and then quenched in ice brine to prevent the formation of equilibrium phases. Subsequently, as recommended by the manufacturer, the solution-treated specimens were subjected to an isothermal aging treatment at $350{ }^{\circ} \mathrm{C}$ for various times in a molten salt

Table 1 Composition of the specimen alloy

\begin{tabular}{lllllll}
\hline Composition & $\mathrm{Au}$ & $\mathrm{Ag}$ & $\mathrm{Cu}$ & $\mathrm{Pd}$ & $\mathrm{Zn}$ & $\mathrm{Ir}$ \\
\hline wt.\% & 50.0 & 34.0 & 12.0 & 3.0 & $<1$ & $<1$ \\
at.\% & 31.88 & 39.58 & 23.71 & 3.54 & 0.96 & 0.33 \\
\hline
\end{tabular}

bath $\left(25 \mathrm{KNO}_{3}+30 \mathrm{KNO}_{2}+25 \mathrm{NaNO}_{3}+20 \mathrm{NaNO}_{2}\right.$, wt.\%), and then quenched in ice brine.

Hardness test

To investigate the hardening and softening behaviour during the aging process, the hardness of the heat-treated plate specimens was measured using a Vickers micro-hardness tester (MVK-H1, Akashi Co., Akashi, Hyogo, Japan) with a 300 -gf load and a holding time of $10 \mathrm{~s}$. The result values are the average of five measurements.

XRD study

XRD study was performed to examine the phase transformation during the aging process. Powder specimens with particle sizes below $45 \mu \mathrm{m}$ were filed using a diamond disc and passed through a 330-mesh screen. The specimens were then mixed with alumina powders with particle sizes of $1 \mu \mathrm{m}$ to prevent sintering agglomeration during heat treatment. Subsequently, the powder specimens were subjected to vacuum sealing in silica tubes and heat treatment, and the alumina powders were filtered from the heat-treated specimens. XRD profile was recorded by X-ray diffractometer (XPERTPRO, Philips, Eindhoven, Netherlands) at $30 \mathrm{kV}$ and $40 \mathrm{~mA}$ using Ni-filtered $\mathrm{Cu} \mathrm{k} \alpha$ radiation as incident beam.

\section{FE-SEM observation}

FE-SEM micrographs of the heat-treated plate specimens were taken to examine the microstructural changes during the aging process. The heat-treated specimens were treated with a polisher and etched with an aqueous solution containing $\mathrm{KCN}$ of $10 \%$ (potassium cyanide) and $\left(\mathrm{NH}_{4}\right)_{2} \mathrm{~S}_{2} \mathrm{O}_{8}$ (ammonium persulfate) of $10 \%$. The surfaces of the heat-treated specimens were observed by FE-SEM (JSM-6700 F, Jeol, Akishima-shi, Tokyo, Japan) at 15 kV.

EDS analysis

The EDS (INCA X-Sight, Oxford Instruments Ltd., Oxford, UK) profile of the heat-treated plate specimen was recorded at $15 \mathrm{kV}$ to examine the changes in the elemental distribution during the aging process.

\section{Results and discussion}

Age-hardening behaviour

Figure 1 shows the isothermal age-hardening curve of the plate specimen solution-treated at $750{ }^{\circ} \mathrm{C}$ for $15 \mathrm{~min}$ and aged at $350{ }^{\circ} \mathrm{C}$ for various times $(\sim 20,000 \mathrm{~min})$. The hardness 
Fig. 1 Isothermal age-hardening curve of the plate specimen solution-treated at $750{ }^{\circ} \mathrm{C}$ for $15 \mathrm{~min}$ and then aged at $350^{\circ} \mathrm{C}$ for various times until 20,000 $\mathrm{min}$

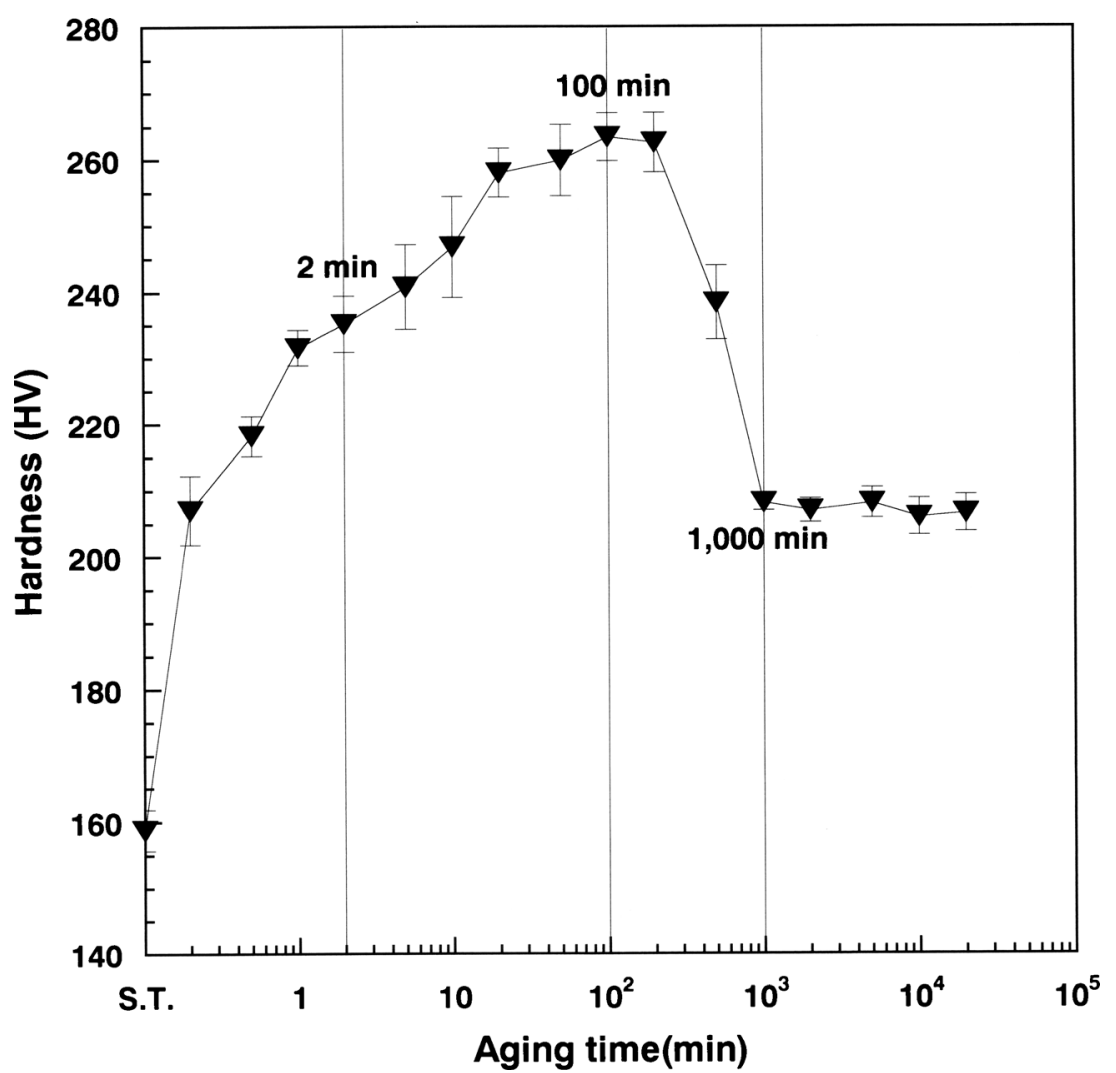

increased rapidly within only $12 \mathrm{~s}$ without an incubation period. At an aging time of $2 \mathrm{~min}$, the hardness increased to $235 \mathrm{HV}$, which was approximately 1.5 times higher than that of the solution-treated specimen (159 HV). Subsequently, the increasing rate of the hardness decreased gradually and finally, the maximum value (263 HV) was obtained at an aging time of $100 \mathrm{~min}$. After maintaining the maximum value for $200 \mathrm{~min}$, the hardness decreased rapidly to $208 \mathrm{HV}$ until $1,000 \mathrm{~min}$, after which, there was no further decrease in hardness until an aging time of 20,000 min.

\section{Phase transformation}

Figure 2 presents the XRD profile of the powder specimens solution-treated at $750{ }^{\circ} \mathrm{C}$ for $15 \mathrm{~min}$ and aged at $350{ }^{\circ} \mathrm{C}$ for various times $(\sim 20,000 \mathrm{~min})$. In the XRD patterns of the specimen solution-treated at $750{ }^{\circ} \mathrm{C}$ for $15 \mathrm{~min}$, a single $\alpha_{0}$ phase with a face-centered cubic (f.c.c.) structure and a lattice constant of $a_{200}=3.97 \AA$ was observed. By aging the specimen isothermally at $350{ }^{\circ} \mathrm{C}$ for $20,000 \mathrm{~min}$, the $\alpha_{0}$ phase was separated into an f.c.c. Ag-rich $\alpha_{1}$ phase with a lattice constant of $a_{200}=4.06 \AA$, and an $\mathrm{AuCu}$ I phase with a facecentered tetragonal (f.c.t.) structure and lattice constants of $a_{200}=3.89 \AA$ and $c_{001}=3.67 \AA$.

In the XRD patterns of the specimen aged at $350{ }^{\circ} \mathrm{C}$ for $12 \mathrm{~s}$, both sides of the (111) $\alpha_{0}$ diffraction peak broadened as the phase decomposition was initiated. Compared to the isothermal age-hardening curve, this corresponds to the rapid increase in hardness that occurred within $12 \mathrm{~s}$. In the XRD patterns at an aging time of $2 \mathrm{~min}$, when the hardness increased apparently to $235 \mathrm{HV}$, the diffraction peaks for the stable Ag-rich $\alpha_{1}$ and AuCu I phases were observed clearly at lower and higher angles of the (111) $\alpha_{0}$ diffraction peak, respectively. In addition, the diffraction peaks of the metastable Ag-rich $\alpha_{1}{ }^{\prime}$ and $\mathrm{AuCu} \mathrm{I}^{\prime}$ phases with higher intensity were observed closer at both sides of the (111) $\alpha_{0}$ diffraction peak. Furthermore, side bands appeared much closer at both sides of the (111) $\alpha_{0}$ diffraction peak, and moved closer with increasing aging time, as observed from the vertical solid lines in Fig. 2 [2, 3, 6, 7]. The appearance of the side bands and rapid increase in hardness suggest that separation of the parent $\alpha_{0}$ phase occurred by spinodal decomposition, not by a nucleation and growth mechanism at $350{ }^{\circ} \mathrm{C}$, and the apparent increase in hardness until $2 \mathrm{~min}$ was caused mainly by the formation of the metastable Ag-rich $\alpha_{1}{ }^{\prime}$ and $\mathrm{AuCu} \mathrm{I}^{\prime}$ phases through this process.

In the XRD patterns at an aging time of $10 \mathrm{~min}$, when the hardness increased to $250 \mathrm{HV}$, the superlattice (110) $\mathrm{AuCu} \mathrm{I}$ diffraction peak $\left(2 \theta=32.6^{\circ}\right)$ appeared as atomic ordering progressed. In the diffraction peak of the Ag-rich phase, the (111) peak intensity of the stable phase $\left(\alpha_{1}\right)$ was stronger than that of the metastable phase $\left(\alpha_{1}{ }^{\prime}\right)$, but the (200) peak intensity 
Fig. 2 XRD profile of the powder specimens solutiontreated at $750{ }^{\circ} \mathrm{C}$ for $15 \mathrm{~min}$ and aged at $350{ }^{\circ} \mathrm{C}$ for various times until 20,000 $\mathrm{min}$. (prime symbol ( ' ): metastable phase, I: $\mathrm{AuCu}$ I)

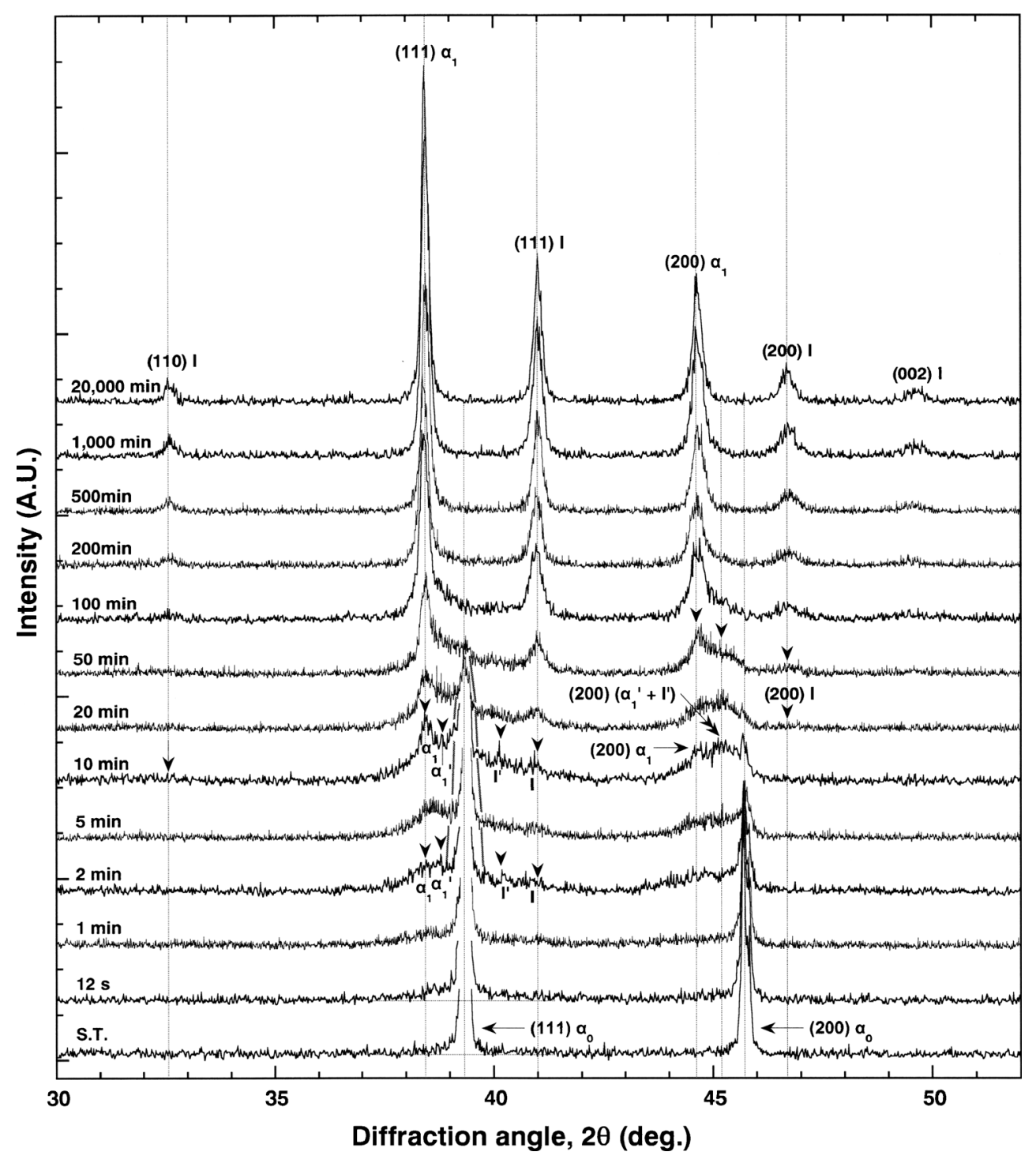

of the stable phase $\left(\alpha_{1}\right)$ was weaker than that of the metastable phase $\left(\alpha_{1}{ }^{\prime}\right)$. In addition, the (200) AuCu I' diffraction peak was not observed, even though the intensity of the (111) $\mathrm{AuCu}$ I' diffraction peak was relatively strong. From such a fact, the (200) diffraction peaks of the metastable Ag-rich $\alpha_{1}{ }^{\prime}$ and $\mathrm{AuCu} \mathrm{I}^{\prime}$ phases appeared to be superimposed, as marked by a double arrow. Thus, these phases must have had coherent interfaces at the (200) plane [8]. Therefore, the hardening resulted from the coherency lattice strain that occurred along the $a$-axis between the metastable Ag-rich $\alpha_{1}{ }^{\prime}$ and $\mathrm{AuCu} \mathrm{I}$ phases, in addition to the lattice distortion that occurred along the $c$-axis between the stable Ag-rich $\alpha_{1}$ and $\mathrm{AuCu}$ I phases by the tetragonality of the $\mathrm{AuCu}$ I ordered phase.

In the XRD patterns at an aging time of $20 \mathrm{~min}$, when the hardness value slightly increased to $258 \mathrm{HV}$, the (200) AuCu I diffraction peak appeared at a higher diffraction angle $(2 \theta=$ $46.7^{\circ}$ ) than the common (200) (Ag-rich $\alpha_{1}{ }^{\prime}+\mathrm{AuCu} \mathrm{I}$ ) diffraction peak. At an aging time of 50-200 min, the intensity of the (200) diffraction peaks for the stable Ag-rich $\alpha_{1}$ and $\mathrm{AuCu}$ I phases became stronger at both sides of the common (200) (Ag-rich $\alpha_{1}{ }^{\prime}+\mathrm{AuCu} \mathrm{I}$ ) diffraction peak, as marked by the arrow. Therefore, the coherency along the (200) plane was lost as the metastable phases transformed to the stable Ag-rich $\alpha_{1}$ and $\mathrm{AuCu}$ I phases.

Subsequently, the diffraction peaks of the metastable Agrich $\alpha_{1}{ }^{\prime}$ and $\mathrm{AuCu} \mathrm{I}^{\prime}$ phases disappeared, and there were no further changes in the XRD patterns after 1,000 min. The hardness increased at a decreasing rate during the formation of the stable Ag-rich $\alpha_{1}$ and $\mathrm{AuCu}$ I phases from the metastable state. Therefore, the hardening effect by the transformation of the stable Ag-rich $\alpha_{1}$ and $\mathrm{AuCu}$ I phases from the metastable state was weaker than that by the spinodal decomposition of the parent $\alpha_{0}$ phase to the metastable Agrich $\alpha_{1}{ }^{\prime}$ and $\mathrm{AuCu} \mathrm{I}^{\prime}$ phases. This resulted from the microstructural changes related to the phase transformation, as is discussed in the "Microstructural changes" section. 
Figure 3 presents the full width at half maximum (FWHM) graph of the powder specimens solution-treated at $750{ }^{\circ} \mathrm{C}$ for $15 \mathrm{~min}$ and aged at $350{ }^{\circ} \mathrm{C}$ for various times $(\sim 20,000 \mathrm{~min})$. The FWHM of the parent $\alpha_{0}$ phase increased as the diffraction peaks of the metastable Ag-rich $\alpha_{1}{ }^{\prime} \cdot \mathrm{AuCu} \mathrm{I}^{\prime}$ and stable Ag-rich $\alpha_{1} \cdot \mathrm{AuCu}$ I phases appeared. Subsequently, the FWHM of the parent $\alpha_{0}$ phase decreased as the $\alpha_{0}$ phase disappeared. The FWHM of the stable Agrich $\alpha_{1}$ and $\mathrm{AuCu}$ I phases reached the maximum value at an aging time of 20 and $100 \mathrm{~min}$, respectively. The FWHM then declined to the minimum value at an aging time of 500 and 1, $000 \mathrm{~min}$, respectively. This suggests that the changing aspect of the FWHM was similar to that of the isothermal agehardening curve. The increase in the FWHM and its subsequent decrease by a phase transformation indicate the formation of lattice strain and its subsequent release in the alloy [9-13]. Therefore, it is considered that both the stable Ag-rich $\alpha_{1}$ and $\mathrm{AuCu}$ I phases were related to hardening and subsequent softening.

\section{Microstructural changes}

Figure 4 shows FE-SEM micrographs of the plate specimens solution-treated at $750{ }^{\circ} \mathrm{C}$ for $15 \mathrm{~min}$ (a) and aged at $350{ }^{\circ} \mathrm{C}$ for $10 \mathrm{~min}$ (b), $100 \mathrm{~min}$ (c), $500 \mathrm{~min}$ (d), 1,000 $\mathrm{min}$ (e) and 20,000 $\mathrm{min}$ (f) at magnifications of $\times 2,000 \quad(1), \times 8,000 \quad(2)$ and $\times 20,000 \quad(3)$. In the specimen solution-treated at $750{ }^{\circ} \mathrm{C}$ for $15 \mathrm{~min}$ (a), an equiaxed structure of a single phase was observed. In the specimen aged at $350{ }^{\circ} \mathrm{C}$ for $10 \mathrm{~min}$ (b), parts of the grain boundaries were replaced with lamellar structures, whereas no apparent changes were observed in the grain interior. In the corresponding XRD patterns, five phases of the parent $\alpha_{0}$, metastable Ag-rich $\alpha_{1}{ }^{\prime}$. $\mathrm{AuCu} \mathrm{I}^{\prime}$ and stable Ag-rich $\alpha_{1} \cdot \mathrm{AuCu}$ I were detected. From the fact that the diffraction peaks of the stable Ag-rich $\alpha_{1}$ and $\mathrm{AuCu}$ I, which are the final product phases, appeared within a short period of aging time (12 s), it is thought that the lamellar structures in the grain boundaries were transformed directly from the parent $\alpha_{0}$ phase to the stable Ag-rich $\alpha_{1}$ and $\mathrm{AuCu}$ I phases without a metastable state considering that the atomic diffusion in the grain boundaries occurs relatively fast [14]. The peak intensity of the stable phases was relatively high in the XRD patterns at $10 \mathrm{~min}$, whereas the ratio of the lamellar structures in the matrix was relatively low in the corresponding FE-SEM micrographs. Therefore, it is thought that parts of the grain interior were also composed of the stable Ag-rich $\alpha_{1}$ and $\mathrm{AuCu}$ I phases. Hence, the grain interior was in the process of spinodal decomposition from the parent $\alpha_{0}$ phase to the metastable Ag-rich $\alpha_{1}{ }^{\prime}$ and $\mathrm{AuCu} \mathrm{I}^{\prime}$ phases, which had coherency, or was in the process of a subsequent transformation from a metastable state to the stable Ag-rich $\alpha_{1}$ and $\mathrm{AuCu} \mathrm{I}$ phases.
Fig. 3 FWHM graph obtained from the (111) diffraction peaks of the $\alpha_{0}$, stable Ag-rich $\alpha_{1}$ and $\mathrm{AuCu} I$ phases with aging at $350{ }^{\circ} \mathrm{C}$

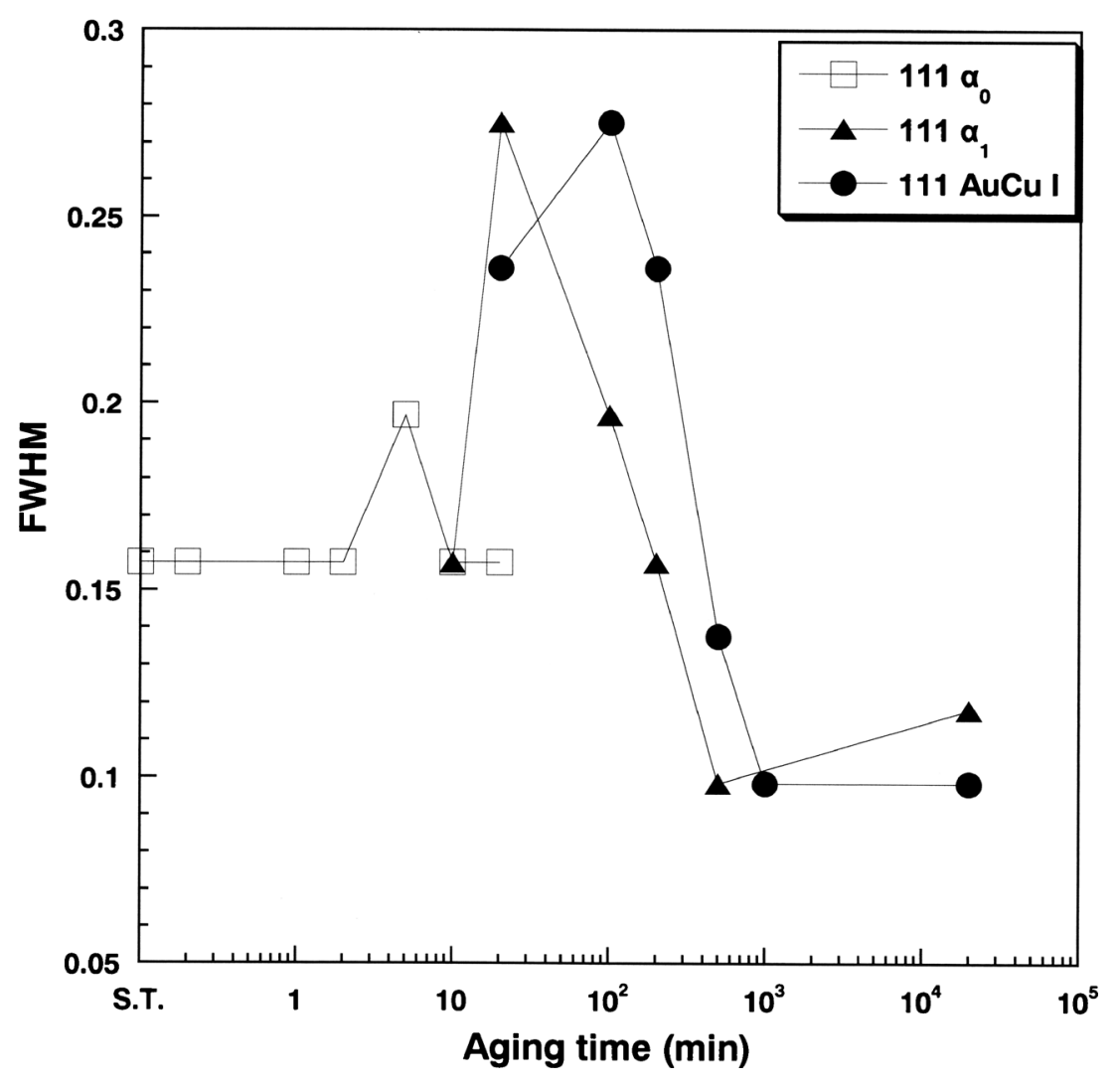



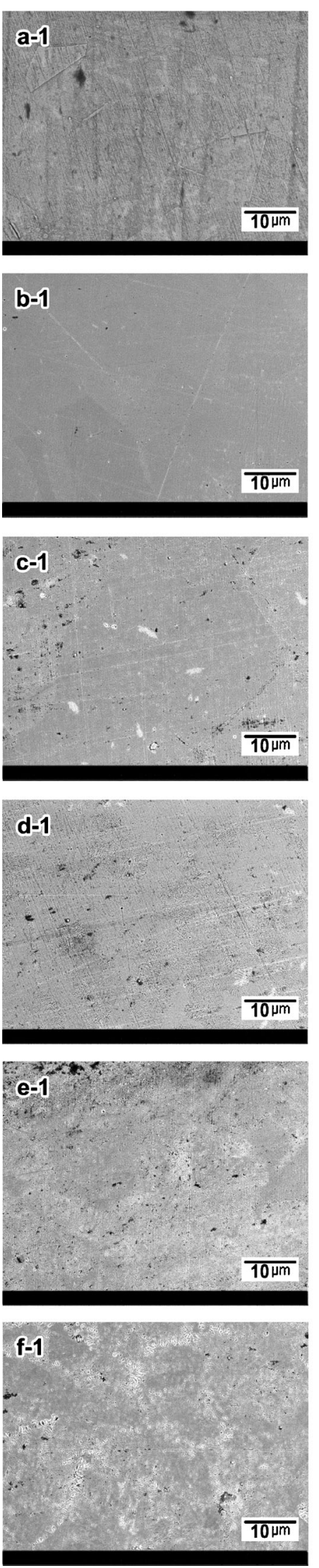

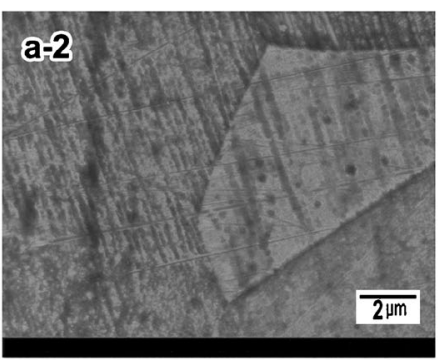

\section{b-2}

$\overline{2^{\mu m}}$
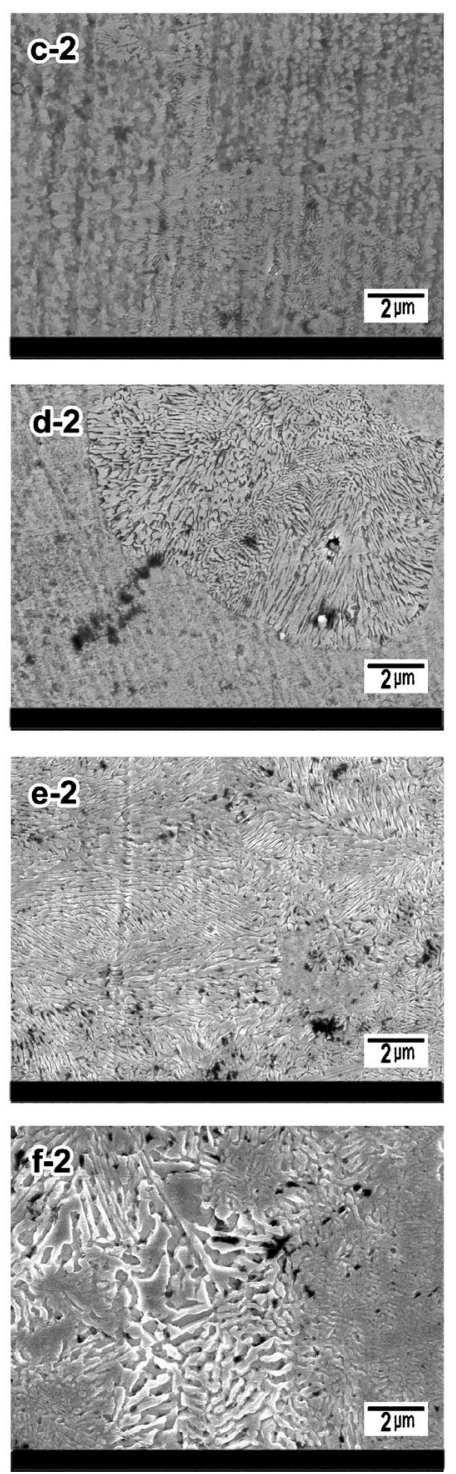
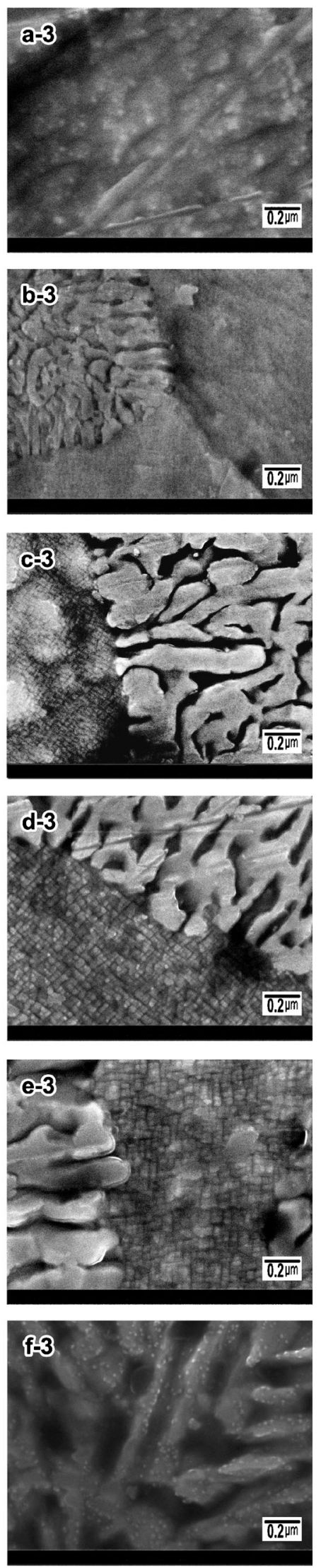

Fig. 4 FE-SEM micrographs of the plate specimens solution-treated at $750{ }^{\circ} \mathrm{C}$ for $15 \mathrm{~min}(\mathbf{a})$ and aged at $350{ }^{\circ} \mathrm{C}$ for $10 \mathrm{~min}(\mathbf{b}), 100 \mathrm{~min}(\mathbf{c}), 500 \mathrm{~min}$ (d), 1,000 $\mathrm{min}(\mathbf{e})$ and 20,000 $\mathrm{min}(\mathbf{f})$ at magnifications of $\times 2,000(1), \times 8,000(2)$ and $\times 20,000(3)$ 
In the specimen aged at $350{ }^{\circ} \mathrm{C}$ for $100 \mathrm{~min}(\mathrm{c})$, the growth of lamellar structures was barely observed at the grain boundaries, and the grain interior was replaced with fine cuboidal structures surrounded by a solute-depleted matrix.
Such fine and uniform structures are characteristic that are obtained through spinodal decomposition [3,5]. The XRD patterns at an aging time of 10-100 min showed that the transformation of the metastable $\mathrm{Ag}$-rich $\alpha_{1}{ }^{\prime}$ and $\mathrm{AuCu} \mathrm{I}$
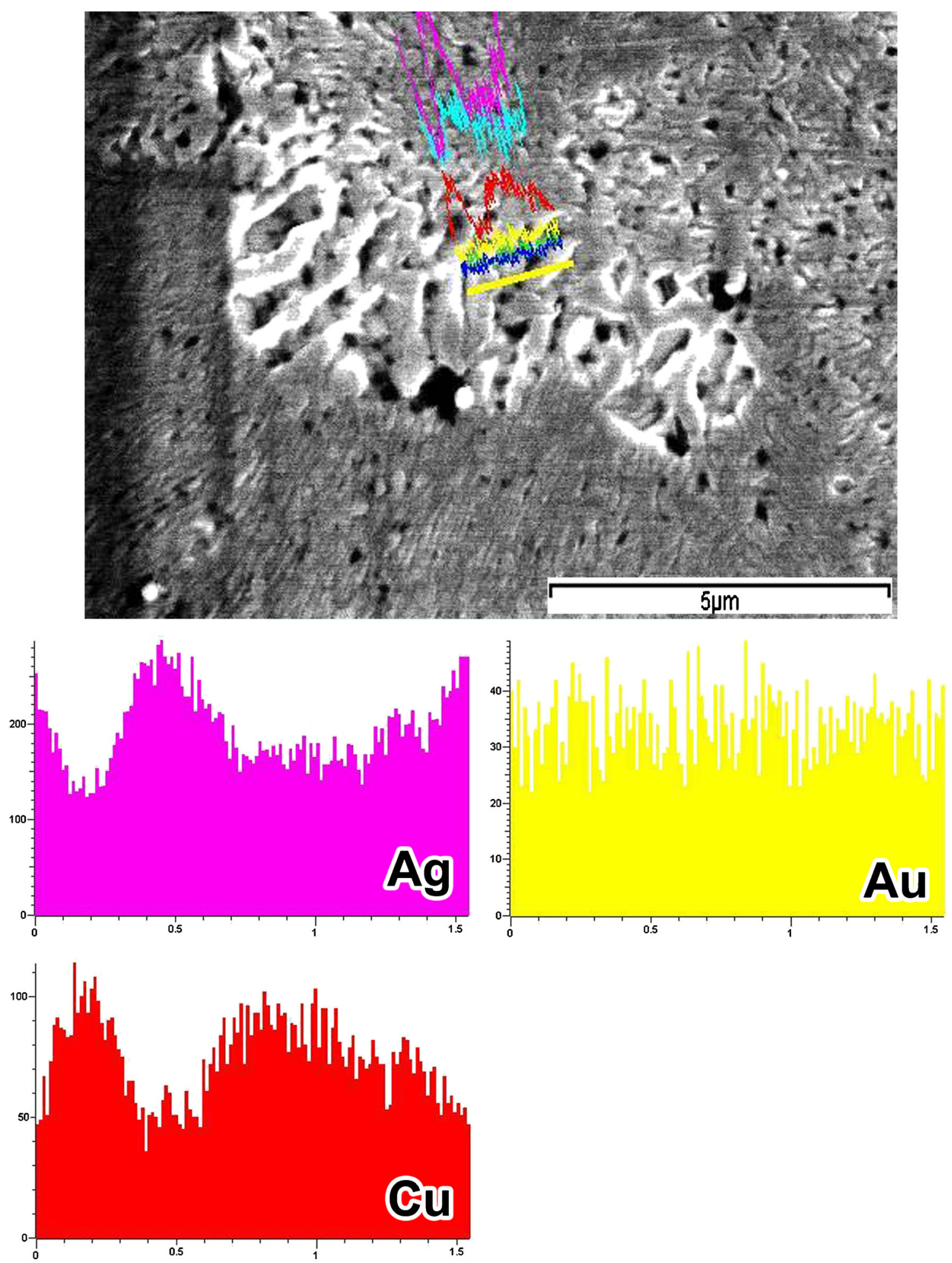

Fig. 5 FE-SEM micrograph and EDS line profile of the plate specimen aged at $350{ }^{\circ} \mathrm{C}$ for 20,000 min after the solution treatment at $750{ }^{\circ} \mathrm{C}$ for 15 min 
phases to the stable state was almost complete. Therefore, it is considered that not only the lamellar structures at the grain boundaries but also the cuboidal structures and surrounding matrix were composed of the stable $\mathrm{Ag}$-rich $\alpha_{1}$ and $\mathrm{AuCu}$ I phases, and their interfaces lost coherency. The cuboidal structures with incoherent interfaces observed at $100 \mathrm{~min}$ were much coarser than the grain interior structures that were observed at $10 \mathrm{~min}$. A comparison with the isothermal agehardening curve showed that this period corresponded to the stage that the hardness increased at a decreasing rate. Therefore, it is considered that the formation of these cuboidal structures compensated for the increase in internal lattice strain resulted from the increased gap in lattice parameters through the phase transformation from the metastable to stable state.

In the specimen aged at $350{ }^{\circ} \mathrm{C}$ for $500 \mathrm{~min}(\mathrm{~d})$, the cuboidal structures became slightly coarser, and approximately half of the matrix was replaced with the lamellar structures formed by the grain boundary reaction. A comparison with the isothermal age-hardening curve showed that this period corresponded to the stage where a rapid decrease in hardness was observed. Therefore, the replacement of the fine cuboidal structures with the coarser lamellar structures without a phase transformation resulted in the release of internal lattice strain by reducing the interfaces between the two phases of the stable Ag-rich $\alpha_{1}$ and $\mathrm{AuCu} \mathrm{I}$. This can be supported by a study of a low-carat gold alloy, which showed that an extremely restricted grain boundary reaction apparently retarded the softening of the spinodally decomposed cuboidal structures [5].

In the specimen aged at $350{ }^{\circ} \mathrm{C}$ for $1,000 \mathrm{~min}(\mathrm{e})$, the lamellar structures did not coarsen further, but they grew and covered most of the matrix. The cuboidal structures were left in an extremely limited area. A comparison with the isothermal age-hardening curve showed that this period corresponded to the stage that the hardness declined to the minimum value. Therefore, the decreasing rate of hardness is thought to be in proportion to the amount of the lamellar structures. In the specimen aged at $350{ }^{\circ} \mathrm{C}$ for $20,000 \mathrm{~min}$ (f), a second grain boundary reaction was initiated to form coarser lamellar structures by consuming the preformed fine lamellar structures from the grain boundaries. Because it occurred after the phase transformation was complete, it is considered that a second grain boundary reaction occurred to reduce the interface energy, regardless the phase transformation. A second grain boundary reaction in dental alloys was reported to cause a decrease in hardness [15]. On the other hand, further softening was not observed in the present study due to the slow progress of the reaction.

\section{Elemental distribution}

Figure 5 presents FE-SEM micrograph of the plate specimen aged at $350{ }^{\circ} \mathrm{C}$ for $20,000 \mathrm{~min}$ after the solution treatment, and

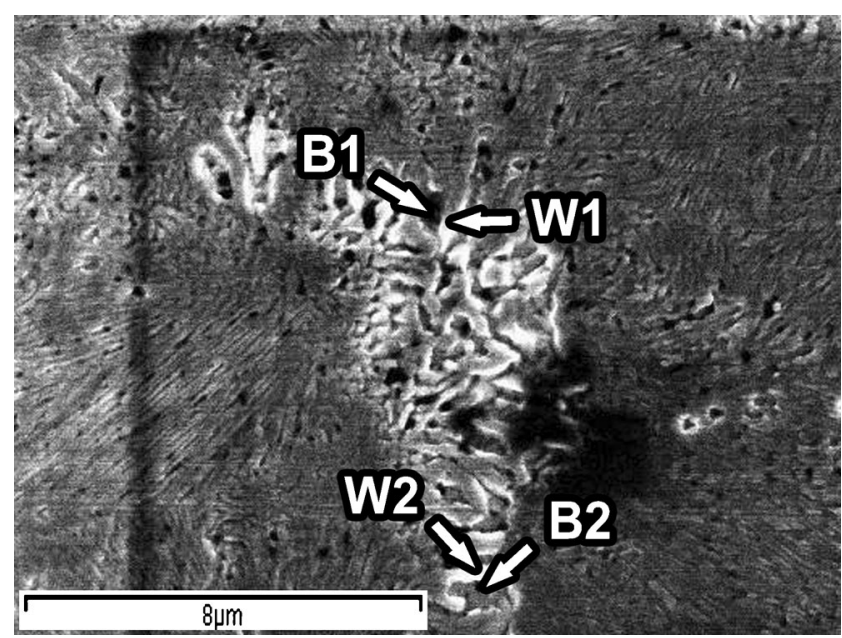

Fig. 6 FE-SEM micrograph of the plate specimen aged at $350{ }^{\circ} \mathrm{C}$ for $20,000 \mathrm{~min}$ after the solution treatment at $750{ }^{\circ} \mathrm{C}$ for $15 \mathrm{~min}$

its EDS line profile obtained by crossing the coarsened lamellar structure. The result showed that the distribution of $\mathrm{Ag}$ and $\mathrm{Cu}$ was inversely proportional to each other whereas the Au content was relatively homogeneous.

The elemental distribution of the lamellar structure was detected more precisely by EDS point analysis (Fig. 6). Table 2 lists the EDS point analysis result for each neighbouring layer of the lamellar structures (black:B/white:W). The result showed that the coarse lamellar structure consisted of alternate $\mathrm{Ag}$-rich and $\mathrm{Cu}$-rich layers, and the $\mathrm{Pd}$ and $\mathrm{Zn}$ content was concentrated in the $\mathrm{Cu}$-rich layer. These minor ingredients resulted in a dissimilarity in the lattice constants of the $\mathrm{AuCu}$ I phase with the values $(a=3.966 \AA$, $c=3.673 \AA$ ) reported by Villars and Calvert [16]. The contrary distribution of $\mathrm{Ag}$ and $\mathrm{Cu}$ resulted from the solubility limit for each other, whereas $\mathrm{Au}$ was soluble with $\mathrm{Ag}$ and $\mathrm{Cu}$ at all atomic ratios [17]. In the present study, at the point where the maximum hardness was obtained, the grain interior had fine and uniform structures that were similar to the single-phased structure due to spinodal decomposition. In addition, the grain boundary reaction was restrained until that point. Such aspects of the alloy will be beneficial to tarnish and corrosion resistance as well as biocompatibility for use in dental practice.

Table 2 Point analysis result by EDS of the specimen at the regions indicated in Fig. 6

\begin{tabular}{lllllll}
\hline Region (at.\%) & $\mathrm{Au}$ & $\mathrm{Ag}$ & $\mathrm{Cu}$ & $\mathrm{Pd}$ & $\mathrm{Zn}$ & $\mathrm{Ir}$ \\
\hline B1 & 33.0 & 54.2 & 12.8 & 0 & 0 & 0 \\
B2 & 33.3 & 57.3 & 9.4 & 0 & 0 & 0 \\
W1 & 30.6 & 6.1 & 55.0 & 4.8 & 3.5 & 0 \\
W2 & 28.7 & 3.5 & 60.1 & 4.6 & 3.1 & 0 \\
\hline
\end{tabular}




\section{Conclusions}

This study examined the spinodal decomposition related to age-hardening and cuboidal structures in a dental low-carat gold alloy with a relatively high $\mathrm{Cu} / \mathrm{Ag}$ content ratio, and the following results were obtained.

(1) Separation of the parent $\alpha_{0}$ phase occurred by spinodal decomposition during aging at $350{ }^{\circ} \mathrm{C}$ after the solution treatment at $750{ }^{\circ} \mathrm{C}$, not by a nucleation and growth mechanism, resulting in the formation of the stable Ag-rich $\alpha_{1}$ and $\mathrm{AuCu}$ I phases through a metastable state.

(2) Hardening resulted from the coherency lattice strain that occurred along the $a$-axis between the metastable Agrich $\alpha_{1}{ }^{\prime}$ and $\mathrm{AuCu} \mathrm{I}$ phases, in addition to the lattice distortion that occurred along the $c$-axis between the stable Ag-rich $\alpha_{1}$ and $\mathrm{AuCu}$ I phases due to the tetragonality of the $\mathrm{AuCu}$ I ordered phase.

(3) The transformation of the stable Ag-rich $\alpha_{1}$ and $\mathrm{AuCu}$ I phases from the metastable state induced the formation of the fine and uniform cuboidal structures, which compensated for the increased gap in lattice parameters through a phase transformation.

(4) The replacement of fine cuboidal structures with coarser lamellar structures occurred without a phase transformation, and resulted in softening by the reducing interfaces between the stable Ag-rich $\alpha_{1}$ and $\mathrm{AuCu} \mathrm{I}$ phases.

Acknowledgements This research was supported by Basic Science Research Program through the National Research Foundation of Korea (NRF) funded by the Ministry of Education, Science and Technology (grant number: 2011-0010995)

Open Access This article is distributed under the terms of the Creative Commons Attribution License which permits any use, distribution, and reproduction in any medium, provided the original author(s) and the source are credited.

\section{References}

1. Yasuda K (1987) Age-hardening and related phase transformations in dental gold alloys. Gold Bull 20:90-103

2. Hamasaki K, Hisatsune K, Udoh K, Tanaka Y, Iijima Y, Takagi O, Naruse S (1998) Ageing behaviour in a dental low-gold alloy with high copper content. J Mater Sci Mater Med 9:213-219

3. Nakagawa M, Yasuda K (1988) Age-hardening and the associated phase transformation in an $\mathrm{Au}-55.2 \mathrm{at} \% \mathrm{Cu}-17.4 \mathrm{at} \% \mathrm{Ag}$ ternary alloy. J Mater Sci 23:2975-2982

4. Hisatsune K, Udoh K, Sosrosoedirdjo BI, Tani T, Yasuda K (1991) Age-hardening characteristics in an $\mathrm{AuCu}-14$ at.\% Ag alloy. J Alloys Compd 176:269-283

5. Park MG, Yu CH, Seol HJ, Kwon YH, Kim HI (2008) Agehardening behaviour of a spinodally decomposed low-carat gold alloy. J Mater Sci 43:1539-1545

6. Udoh K, Fujiyama H, Hisatsune K, Hasaka M, Yasuda K (1992) Age-hardening associated with ordering and spinodal decomposition in a $\mathrm{AgCu}-40 \mathrm{at} \%$ Au pseudobinary alloy. J Mater Sci 27:504-510

7. Yasuda K, Hisatsune K (1993) Microstructure and phase transformations in dental gold alloys. Gold Bull 26:50-66

8. Lee JH, Yi SJ, Seol HJ, Kwon YH, Lee JB, Kim HI (2006) Agehardening by metastable phases in an experimental $\mathrm{Au}-\mathrm{Ag}-\mathrm{Cu}-\mathrm{Pd}$ alloy. J Alloys Compd 425:210-215

9. Douglass DL (1969) Spinodal decomposition in Al/Zn alloys. J Mater Sci 4:130-137

10. Tanaka Y, Udoh K, Hisatsune K, Yasuda K (1998) Early stage of ordering in stoichiometric $\mathrm{AuCu}$ alloy. Mater Trans JIM 39:87-94

11. Kawashima I, Ohno H, Sarkar NK (2000) Effect of Pd or Au addition on age-hardening in AgMn-based alloys. Dent Mater 16:75-79

12. Shiraishi T, Ohta M (2002) Age-hardening behaviors and grain boundary discontinuous precipitation in a Pd-free gold alloy for porcelain bonding. J Mater Sci Mater Med 13:979-983

13. Suryanarayana C, Norton MG (2006) X-ray diffraction - a practical approach, 1st edn. Springer Science \& Business Media, New York, p 89

14. Hisatsune K, Udoh K, Nakagawa M (1990) Aging behavior in a dental low carat gold alloy and its relation to CuAu II. J LessCommon Metals 160:247-258

15. Ohta M, Hisatsune K, Yamane M (1975) Study on age-hardenable silver alloy III on the ageing process of dental $\mathrm{Ag} \mathrm{Pd} \mathrm{Cu} \mathrm{Au}$ alloy. J Jpn Soc Dent Appar Mater 16:87-92

16. Villars P, Calvert LD (1985) Pearson's handbook of crystallographic data for intermetallic phases, American Society for Metals, Metals Park, pp 416-417

17. Massalski TB (1990) Binary alloy phase diagrams, 2nd edn. ASM International, Materials Park, pp 12-13, 28-29, 358-362 